\title{
Peripheral Blood Fibrocytes from Burn Patients: Identification and Quantification of Fibrocytes in Adherent Cells Cultured from Peripheral Blood Mononuclear Cells
}

\author{
Liju Yang, Paul G. Scott, Jennifer Giuffre, Heather A. Shankowsky, Aziz Ghahary, \\ and Edward E. Tredget
}

\begin{abstract}
Department of Surgery, Wound Healing Research Group (LY, JG, HAS, AG, EET), and Division of Plastic and Reconstructive Surgery, Division of Critical Care Medicine (EET), and Department of Biochemistry (PGS), University of Alberta, Edmonton, Alberta, Canada
\end{abstract}

SUMMARY: Peripheral blood fibrocytes are a newly identified leukocyte subpopulation that displays fibroblast-like properties. These blood-borne cells can rapidly enter the site of injury at the same time as circulating inflammatory cells. We hypothesize that circulating fibrocytes represent an important source of fibroblasts for healing of extensive burn wounds where it may be difficult for fibroblasts to migrate from the edges of uninjured tissue. In this study we identified and quantified fibrocytes among the adherent cells cultured from human peripheral blood mononuclear cells (PBMC) obtained from 18 burn patients and 12 normal individuals, based on their ability to express type I collagen. Our results showed that adherent cells cultured from PBMC of burn patients differentiated to fibrocytes more efficiently than did those from normal individuals. The percentage of type I collagen-positive fibrocytes was significantly higher for patients than for controls $(89.7 \pm 7.9 \%$ versus $69.9 \pm 14.7 \%, p<0.001)$. This percentage was consistently higher for patients with a $\geq 30 \%$ total body surface area burn until 1 year, with the highest percentage appearing within 3 weeks of injury. A positive correlation was found between the levels of serum transforming growth factor- $\beta 1$ (TGF- $\beta 1$ ) and the percentage of fibrocytes developing in the cultures of PBMC derived from these patients. We also demonstrated that fibrocytes were derived from $\mathrm{CD} 14^{+}$cells but not CD14- cells. Conditioned medium from $\mathrm{CD}^{-} 4^{-}$cells was, however, required for fibrocyte differentiation, whereas direct contact between $\mathrm{CD}_{1} 4^{-}$and $\mathrm{CD} 14^{+}$cells was not necessary. Treatment of the cell cultures with TGF- $\beta 1$ enhanced the development of collagen-positive cells, whereas the inclusion of neutralizing anti-TGF- $\beta 1$ antibodies in the CD14 conditioned medium suppressed fibrocyte differentiation. These data suggest that the development of fibrocytes is up-regulated systemically in burn patients. Increased TGF- $\beta$ in serum stimulates the differentiation of the $\mathrm{CD} 14^{+}$cell population in PBMC into collagen-producing cells that may be important in wound healing and scarring. (Lab Invest 2002, 82:1183-1192).

\begin{abstract}
$T$ njury to the skin triggers a wound healing process 1 that involves inflammation, cell proliferation and migration, angiogenesis, and extracellular matrix production. Inflammatory cells infiltrate the wound and release various growth factors and cytokines to regulate the functions of other cells in the wound. Dermal fibroblasts are recruited into the wound site where they produce new extracellular matrix proteins, including types I and III collagens, fibronectin, and proteoglycans, leading to scar tissue formation to repair injured tissue (Singer and Clark, 1999). Healing of extensive burn wounds often leads to excessive dep-
\end{abstract}

DOI: 10.1097/01.LAB.0000027841.50269.61

Received April 15, 2002.

This work was supported by the Canadian Institutes of Health Research (EET, AG, PGS) and the Alberta Heritage Foundation for Medical Research (EET).

Address reprint requests to: Dr. Edward E. Tredget, 2D3. 81 WMSHC, 8440-112 Street, University of Alberta, Edmonton, Alberta, Canada, T6G 2B7. E-mail: etredget@gpu.srv.ualberta.ca osition of extracellular matrix in the dermis and the development of hypertrophic scarring (Scott et al, 2000; Tredget et al, 1997). When extensive areas of skin are burned, it may be difficult or impossible for fibroblasts to migrate from the edges of uninjured tissue. It is not known from where and how these cells are recruited into this type of wound.

While studying acute cellular responses in wound repair, Bucala and colleagues (1994) identified a novel leukocyte subpopulation that has fibroblast-like properties. These cells were therefore named fibrocytes. Peripheral blood fibrocytes can rapidly enter the site of injury at the same time as circulating inflammatory cells. They are adherent cells that display a spindleshaped morphology and have the ability to produce extracellular matrix proteins, including types I and III collagens and fibronectin. Fibrocytes display features of hematopoietic cells, such as expression of CD34, and are considered to be stem cells derived from the bone marrow. Although these cells make up only $0.5 \%$ of peripheral blood leukocytes, they constitute $10 \%$ of 
cells infiltrating subcutaneously implanted wound chambers in mice (Bucala et al, 1994). Fibrocytes are potent antigen-presenting cells that can activate $\mathrm{T}$ lymphocytes. They also produce chemoattractants and recruit CD4 ${ }^{+}$T lymphocytes (Chesney et al, 1997). An important role for fibrocytes in cutaneous wound healing in vivo has been postulated based on immunolocalization of CD34 ${ }^{+}$fibroblast-like cells in dermal scar tissue (Bucala et al, 1994; Chesney et al, 1997). The expression of the chemokine receptor CCR7 on fibrocytes and interaction with lymphoid chemokines is involved in the migration of these cells to the wound (Abe et al, 2001). The production of type I collagen by fibrocytes in vitro is regulated by the inflammatory cytokines IL-1 $\beta$ and transforming growth factor- $\beta 1$ (TGF- $\beta 1$ ) (Abe et al, 2001; Chesney et al, 1998). Recently, it has been reported that fibrocytes induce angiogenesis both in vitro and in vivo (Hartlapp et al, 2001). The fact that these blood-borne cells have a broad differentiation capacity suggests an important role in deep dermal and full-thickness skin injury.

We hypothesize that circulating fibrocytes are an important source of fibroblasts and other dermal cells for the healing of large burn wounds. The aims of this study were (1) to determine whether burn patients with extensive skin loss have increased number of fibrocytes in their blood and (2) to investigate the mechanisms that regulate fibrocyte development, in particular the effect of the cytokine TGF- $\beta 1$, which is known to be elevated in the serum of burn patients (Tredget et al, 1998) and plays an important role in wound repair (O'Kane and Ferguson, 1997).

\section{Results \\ Identification of Collagen-Producing Fibrocytes}

We used RT-PCR to examine the specific expression of mRNA for the pro $\alpha 1$ (I) chain of type I collagen in fibrocytes cultured from peripheral blood mononuclear cells (PBMC) of normal individuals and burn patients. A sample of human dermal fibroblast cDNA was amplified by PCR as a positive control for collagen mRNA. A sample of fibrocyte mRNA without reverse transcription was used as a negative control in each PCR. As shown in Figure 1, the 405-bp PCR products expected for the type I collagen pro $\alpha 1$ (I) chain mRNA were observed in cultured fibrocytes from both normal individuals and burn patients. This product was not detected in lymphocytes or freshly isolated PBMC. Equivalent amplification of $\beta$-actin products from these samples suggested that there were no marked differences in the initial amounts of total RNA used in the reverse transcription reactions.

To verify expression of type I collagen at the protein level, immunocytochemistry was performed in fibrocytes subcultured on coverslips. Immunostaining for type I collagen in cultured dermal fibroblasts was used as a positive control. All of the fibroblasts stained for type I collagen intracellularly (Fig. 2a). Some of the spindle-shaped fibrocytes were strongly positive for collagen I, whereas others were stained only weakly

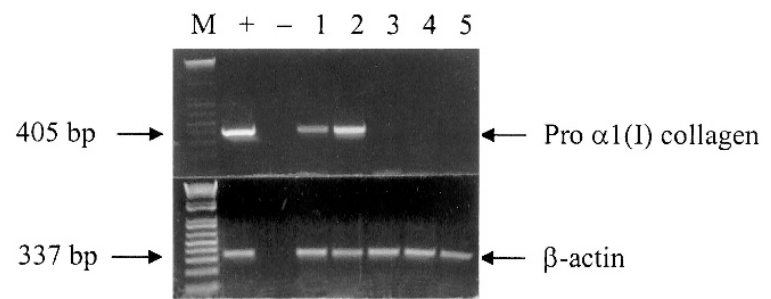

Figure 1.

Expression of type I collagen mRNA in fibrocytes. Cellular RNA was extracted from the cells; expression of mRNA for the pro $\alpha 1$ (I) chain of type I collagen was analyzed by RT-PCR. PCR products were visualized on a $1.2 \%$ agarose gel stained with ethidium bromide. Lane $M$, molecular weight marker; lane +, positive control (fibroblast); lane -, negative control (fibrocyte mRNA without reverse transcription); lane 1 , fibrocytes from a normal individual; lane 2, fibrocytes from a burn patient; lane 3, lymphocytes from a normal individual; lane 4, lymphocytes from a burn patient; lane 5 , freshly isolated peripheral blood mononuclear cells (PBMC). Amplification of $\beta$-actin cDNA in these samples served as an internal control.

(Fig. 2b). A negative control using nonimmune IgG demonstrated the specificity of the staining (Fig. 2c). In addition to having a fibroblast-like morphology, fibrocytes also displayed some features of smooth muscle cells such as a slim bipolar shape. The nuclei of fibrocytes were denser than those of fibroblasts, consistent with a low proliferation rate in culture.

\section{Sizes of Cultured Fibrocytes and Rate of Cell Proliferation}

To compare the size of fibrocytes to fibroblasts, we measured the diameter of each cell type in suspension using a Coulter Counter. The results showed that the size distribution profiles of fibrocytes and fibroblasts were similar, although the fibrocytes were slightly larger (mean diameter $18.5 \mu \mathrm{m}$, compared with 17.5 $\mu \mathrm{m}$ for the fibroblasts).

When comparing their behavior in culture, we found that fibrocytes proliferated more slowly than did fibroblasts. When the same numbers of each type of cell were seeded, fibroblasts reached confluence within 10 days; however, fibrocytes stopped proliferating while still subconfluent.

\section{Different Morphologies of Fibrocytes from Burn Patients and Normal Individuals}

We compared the appearance of fibrocytes cultured from PBMC of burn patients to normal controls under the microscope at various times. After 7 days of culture, spindle-shaped adherent cells started to appear in both normal controls (Fig. 3a) and burn patients (Fig. 3b). After 14 days, fibroblast-like cells represented the main cell population in culture. The numbers of these cells were markedly higher in samples from burn patients (Fig. 3d) compared with normal controls (Fig. 3c). After 32 days, the adherent cells in normal controls became large and swollen (Fig. 3e). In samples from burn patients, however, most of these adherent cells remained spindle-shaped at this time (Fig. 3f). 

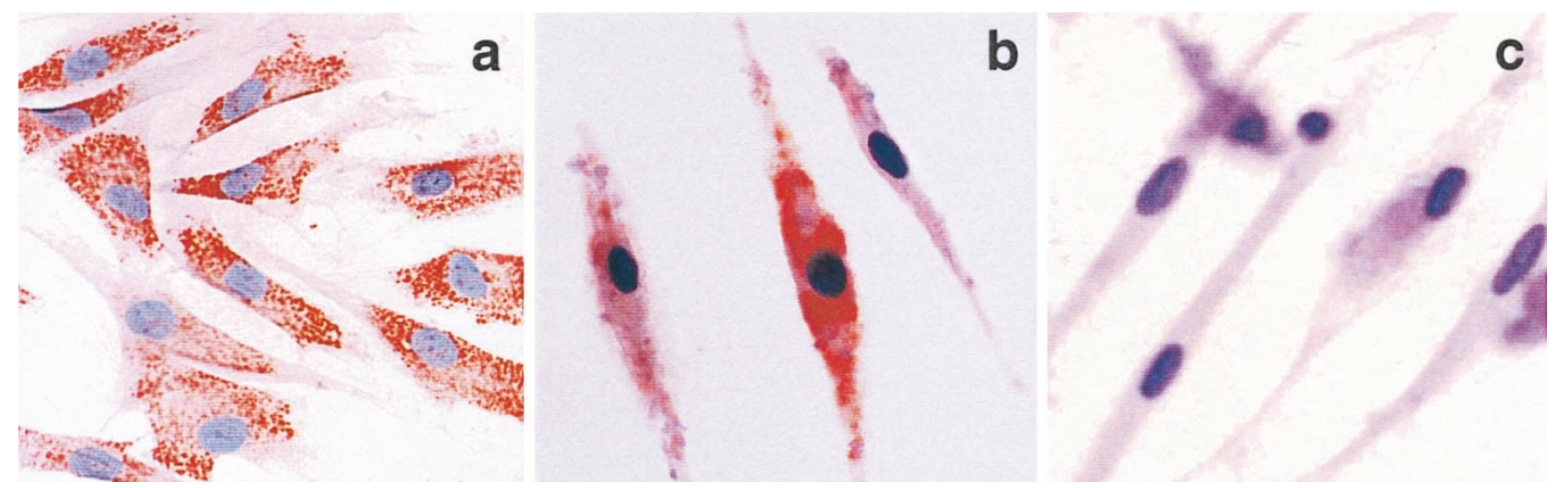

Figure 2.

Immunostaining for type I collagen in fibrocytes. Fibrocytes were subcultured on coverslips and immunostained with a primary antibody specific for human type I collagen followed by a biotinylated secondary antibody. The immunoreactivity was visualized using 3-amino-9-ethylcarbazole. a, Fibroblasts used as positive controls. b, Fibrocytes stained positively for intracellular type I collagen. c, Negative controls of fibrocytes stained with nonimmune IgG. Original magnification, $\times 400$.

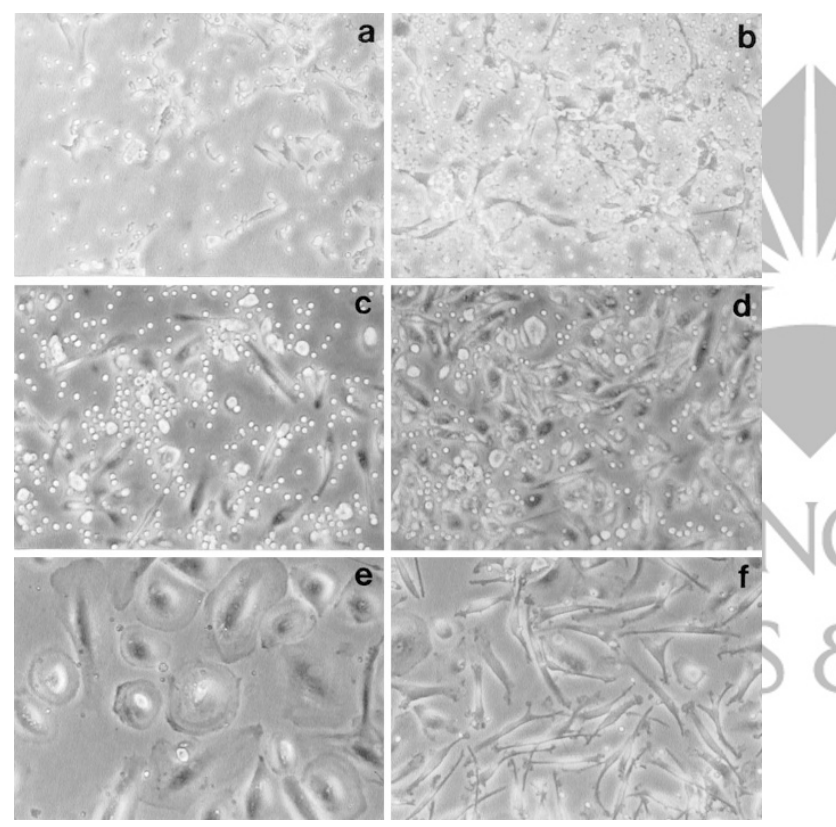

Figure 3.

Prolonged existence of fibrocytes in the cultures of PBMC from burn patients. PBMC isolated from normal individuals (a, c, and e) and burn patients (b, $d$, and f) were cultured in 6-well plates as described in "Materials and Methods" for 7 ( $a$ and $b), 14$ ( $c$ and $d)$, and 28 (e and f) days. Note the marked differences in cell morphologies between $e$ and $f$ and the increased numbers of spindle-shaped fibrocytes from burn patients. Original magnification, $\times 100$.

\section{Burn Patients Yield Adherent Cell Populations with a Higher Percentage of Fibrocytes than Do Normal Individuals}

To determine whether the development of collagenproducing fibrocytes is enhanced systemically after burn injury, we measured the percentage of type I collagen-positive fibrocytes in the adherent cells cultured from PBMC in 18 burn patients and 12 normal individuals. The percentage of fibrocytes was significantly higher for patients than for controls $(89.7 \pm$ $7.9 \%$ versus $69.9 \pm 14.7 \%, p<0.001)$. When analyzing the percentages of fibrocytes in cultures from patients with small versus large burns, the patients with $a \geq 30 \%$ total body surface area (TBSA) burn $(n=$
14) yielded significantly higher percentages of fibrocytes than did those with a $10 \%$ to $29 \%$ TBSA burn ( $n$ $=4)(91.45 \pm 4.79 \%$ versus $75.71 \pm 14.31 \%, p<$ $0.001)$. We also determined the percentages of fibrocytes appearing in the cultures of PBMC from patients with $a \geq 30 \%$ TBSA burn obtained at various times after injury. In comparison with controls, this percentage was consistently higher in patients until 1 year, with the highest percentage appearing within 3 weeks of injury (Fig. 4a). Although there were variations between patients in the percentages of fibrocytes at
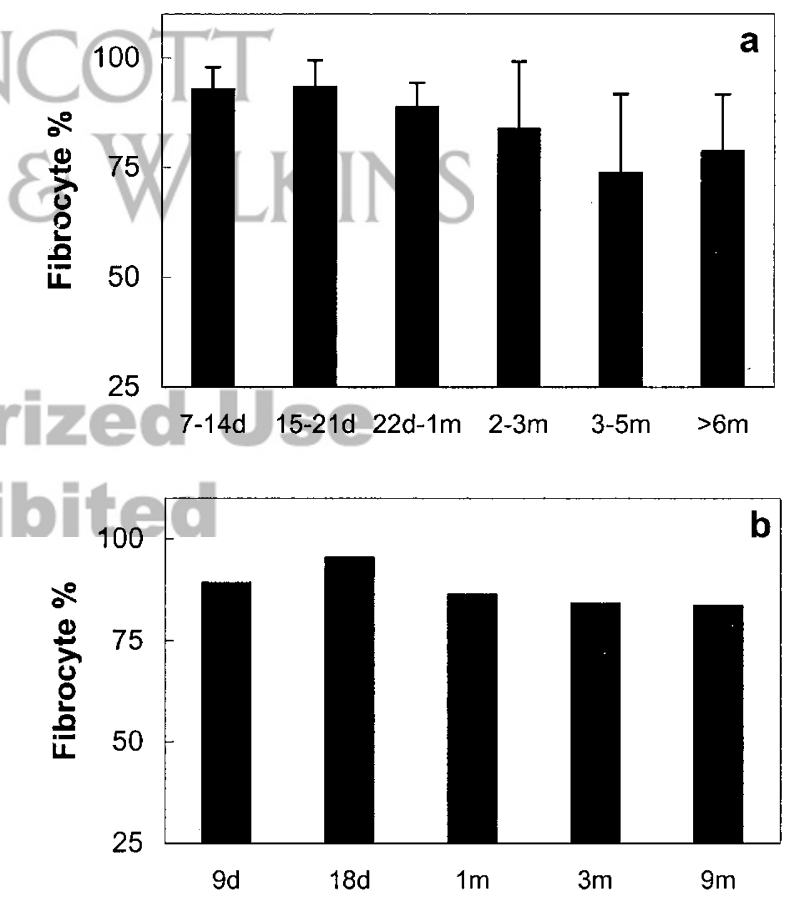

Time Post-burn

Figure 4.

The percentage of type I collagen-positive fibrocytes in the adherent cells cultured from PBMC was increased after burn injury. The percentage of fibrocytes was persistently higher in patients with $\mathrm{a} \geq 30 \%$ total body surface area (TBSA) burn until 1 year postburn; the highest percentage appeared within the first 3 weeks (a). b, Time course of fibrocyte percentage for one representative patient who had a 50\% TBSA burn. 
various times, the time course of fibrocyte differentiation was consistent within individual patients. Figure $4 \mathrm{~b}$ shows representative results for patient 4 who had a $50 \%$ TBSA burn.

\section{Fibrocytes Differentiate from CD14 ${ }^{+}$Cells}

We analyzed the cellular source of fibrocytes in PBMC by purifying $\mathrm{CD}_{14}{ }^{+}$cells from total PBMC using the magnetic cell separation (MACS) system. Flow cytometry demonstrated that the purity of this CD14 ${ }^{+}$population was $92 \%$ to $94 \%$ and that CD14 ${ }^{+}$cells accounted for about $20 \%$ of the total PBMC (data not shown). CD14 ${ }^{+}$and CD14 ${ }^{-}$cells were cultured separately on 6-well plates. After 14 days of culture, fibroblast-like adherent cells were observed only in the $\mathrm{CD}^{+} 4^{+}$cell population (Fig. 5a) and not in the CD14 ${ }^{-}$ cell population (Fig. 5b). These adherent cells were positive for type I collagen (data not shown). These observations show that fibrocytes are derived from the $\mathrm{CD}_{14}{ }^{+}$cell population of PBMC. However, fewer fibroblast-like cells developed in cultures of CD14 cells than in cultures of whole PBMC, suggesting that CD14- lymphocytes promote the differentiation of fibrocytes. We therefore tested the effects of conditioned medium derived from CD14- lymphocytes. $\mathrm{CD}_{14}{ }^{+}$and $\mathrm{CD}_{14}{ }^{-}$cells were cultured separately in 6 -well plates for 24 hours. The $\mathrm{CD}_{14}^{-}$conditioned medium and the CD14- ${ }^{-}$cells were collected into centrifuge tubes. The supernatant was separated from

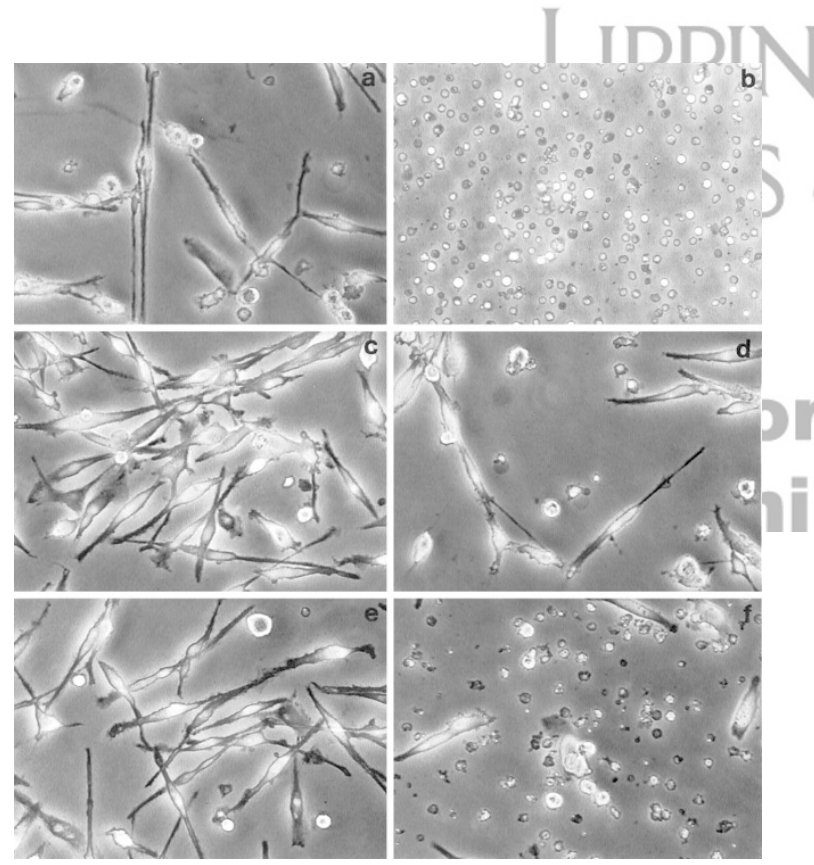

Figure 5.

Fibrocytes are derived from $\mathrm{CD}_{14}{ }^{+}$cells. After 14 days in culture, fibroblastlike cells developed from $\mathrm{CD}_{14}{ }^{+}$cells (a) but not from $\mathrm{CD} 14^{-}$cells (b). Treatment of $\mathrm{CD}_{14}{ }^{+}$cells with the conditioned medium from $\mathrm{CD} 14^{-}$cells markedly increased the number of fibroblast-like cells (c), whereas direct contact between $\mathrm{CD}_{14}{ }^{+}$and $\mathrm{CD} 14^{-}$cells did not (d). Treatment of CD14 ${ }^{+}$ cells with transforming growth factor- $\beta 1$ (TGF- $\beta 1$ ) (e) had the same effect as conditioned medium from $\mathrm{CD} 14^{-}$cells. Neutralizing anti-TGF- $\beta 1$ antibodies added to conditioned medium from $\mathrm{CD} 14^{-}$cells suppressed fibrocyte differentiation (f). Original magnification, $\times 100$. the cells by centrifugation at $2000 \mathrm{rpm}$ for 10 minutes at $4^{\circ} \mathrm{C}$ and subsequently added to $\mathrm{CD} 14^{+}$cells cultured in the 6 -well plates. The CD14 ${ }^{-}$cell pellets were resuspended in culture medium and then added to other wells of CD14 $4^{+}$cells. As shown in Fig. $5 \mathrm{c}$, treatment of $\mathrm{CD}_{14}{ }^{+}$cells with conditioned medium from $\mathrm{CD}_{14}^{-}$cells strikingly increased the number of differentiated fibrocytes, whereas direct contact between $\mathrm{CD}_{14}^{-}$and CD14 ${ }^{+}$cells appeared unnecessary for this process (Fig. $5 d$ ). Because TGF- $\beta 1$ is known to be a powerful stimulator of collagen production by fibroblasts (Ignotz and Massagué, 1986; Varga and Jimenez, 1986), we tested the effect of this cytokine on the differentiation of fibrocytes. CD14 ${ }^{+}$cells were treated with either recombinant human TGF- $\beta 1$ (R\&D Systems, Minneapolis, Minnesota) dissolved in culture medium $(2.5 \mathrm{ng} / \mathrm{ml})$ or with conditioned medium from CD14- ${ }^{-}$cells supplemented with anti-TGF- $\beta 1$ antibody (20 $\mu \mathrm{g} / \mathrm{ml}$; R\&D Systems). Morphologic changes induced by TGF- $\beta 1$ (Fig. 5 e) were similar to those evoked by treatment with conditioned medium from the CD14 ${ }^{-}$cells (Fig. 5c). The inclusion of anti-TGF- $\beta 1$ antibody in conditioned medium from the CD14- cells largely blocked the induction of fibrocytes in cultures of $\mathrm{CD} 14^{+}$cells (Fig. 5f).

\section{The Appearance of Fibrocytes Is Correlated with the Level of Serum TGF- $\beta 1$}

The concentration of TGF- $\beta 1$ in the serum was measured using an ELISA. The levels of total TGF- $\beta 1$ were significantly higher in the sera of burn patients $(n=18)$ in this study, compared with the 12 normal individuals $(82.7 \pm 30.6 \mathrm{ng} / \mathrm{ml}$ versus $43.2 \pm 11.9 \mathrm{ng} / \mathrm{ml}, p<$ $0.001)$. Figure $6 \mathrm{~A}$ shows fibrocyte percentages and levels of serum TGF- $\beta 1$ as a function of time after injury for the whole group of patients (panels a and c) and for one representative individual patient (panels $b$ and $d$ ). Analysis by linear regression (Fig. 6B) suggests that the percentages of fibrocytes that appeared in cultures of PBMC from these patients were positively correlated with levels of serum TGF- $\beta 1$. Because of the variations between results for different burn patients, the overall correlation coefficient $\left(r^{2}\right)$ is rather low (Fig. 6B, upper panel). It is much higher for the multiple measurements made at different times after injury for individual patients. Representative results are shown in Figure 6B, lower panel, for the same patient whose raw data are shown in Figure 6A, panels $b$ and $d$.

\section{TGF- $\beta 1$ Increases the Proliferation and Differentiation of Fibrocytes}

In light of the above observations, we further evaluated the effects of TGF- $\beta 1$ on fibrocyte growth in vitro. PBMC obtained from the blood of normal individuals were cultured in duplicate on 6 -well plates $\left(5 \times 10^{6}\right.$ cells/well) as described. After 4 days, $2.5 \mathrm{ml}$ of recombinant human TGF- $\beta 1(2.5 \mathrm{ng} / \mathrm{ml})$ was added to the treated cells. Control cells were cultured in normal cell culture medium. Cells were continuously cultured for 
A
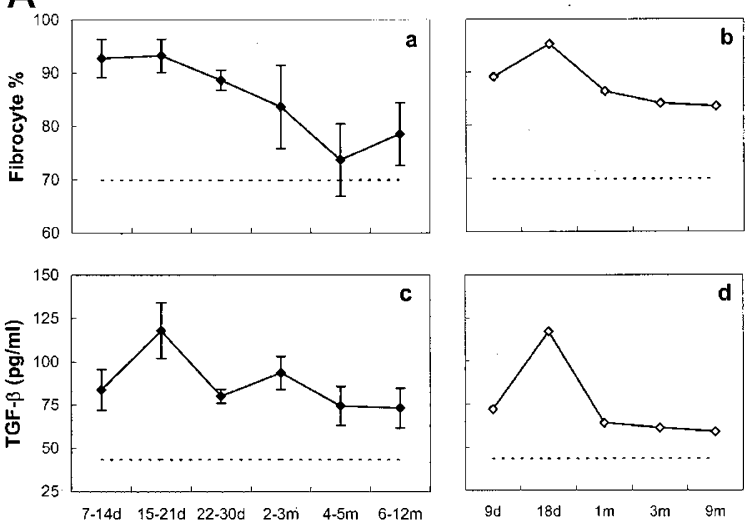

Time Post-burn

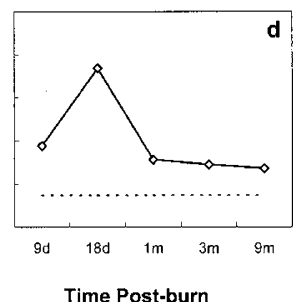

B

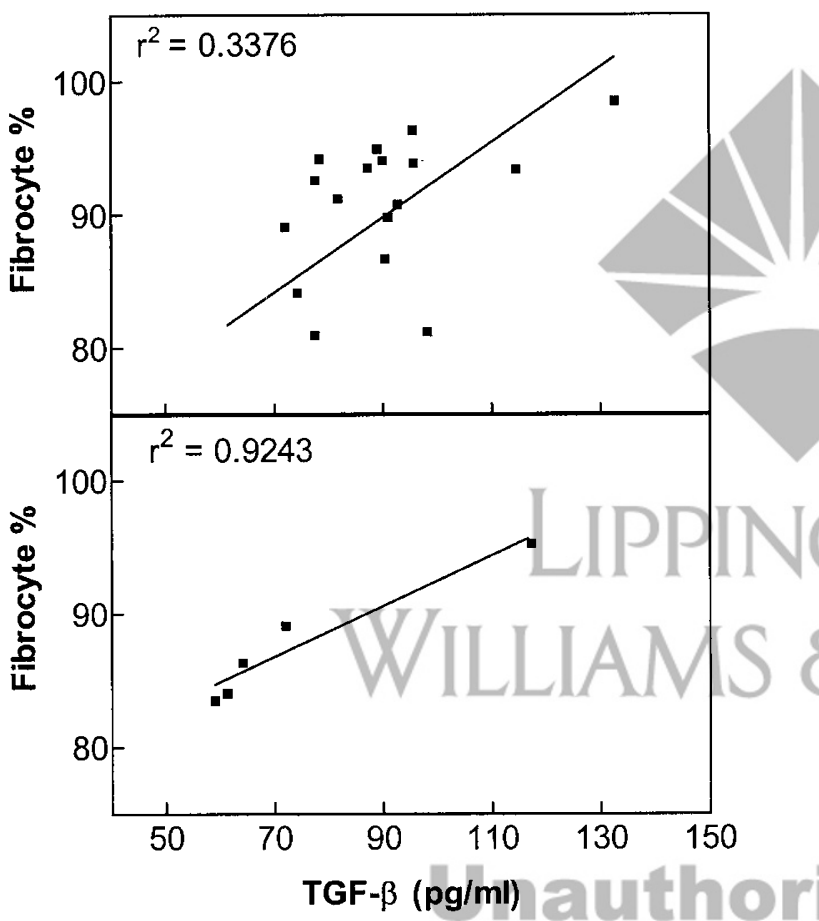

Figure 6.

Correlation between serum TGF- $\beta 1$ levels and fibrocyte numbers. A, Parallel trends of fibrocyte percentage (a) and serum TGF- $\beta 1$ (c) from 18 burn patients with $\geq 30 \%$ TBSA burn. This trend can be seen more clearly for an individual burn patient who had a 50\% TBSA burn (b and d). Dotted line represents the mean values of fibrocyte percentage (upper panels) or serum TGF- $\beta 1$ (lower panels) in 12 normal individuals. B, Correlation between serum TGF- $\beta 1$ and fibrocyte percentage from all patients (upper panel) and the same individual patient (lower panel) as shown in A, panels $b$ and $d$, analyzed by linear regression.

28 days, and the medium was changed twice a week. We found that addition of TGF- $\beta 1$ to culture medium markedly changed the morphology of fibrocytes. These cells displayed a more fibroblast-like morphology with longer projections and more cytoplasm, compared with untreated cells (Fig. 7A). Flow cytometry demonstrated that the percentage of collagen I-positive cells was increased by TGF- $\beta 1$ (Fig. 7B).

We next examined the effect of TGF- $\beta 1$ on fibrocyte proliferation by cell counting. PBMC were cultured on 12-well plates $\left(2.5 \times 10^{6}\right.$ cells/well $)$ in the presence or absence of TGF- $\beta 1$ (2.5 ng/ml). After 7, 14, 21, and 28 days, adherent cells were harvested by incubation with trypsin/EDTA and resuspended in culture medium. The number of cells was counted using a hemocytometer. Our data showed that TGF- $\beta 1$ significantly increased the total number of adherent cells at all time points tested during the culture $(p<0.05$ at Days 7 and 14, $p<0.01$ at Days 21 and 28, $n=6$ ) (Fig. 7C).

\section{Discussion}

The fibrocyte is a novel cell type that may be involved in several aspects of wound repair, including inflammation, production of extracellular matrix, and angiogenesis. Previous investigations have provided evidence that fibrocytes play an important role in human cutaneous wound healing and participate in fibrotic disorders (Chesney et al, 1997, 1998; Grab et al, 1999). The present study is the first to identify and quantify fibrocytes cultured from PBMC of burn patients, based on their ability to express type I collagen, a major protein of connective tissue matrix. Our results have demonstrated that fibrocyte differentiation is up-regulated systemically in patients with large burn injuries. Importantly, we found a positive correlation between the levels of serum TGF- $\beta$ and the proportions of fibrocytes developing in the adherent cell populations derived from PBMC of burn patients.

The capacity of fibrocytes to produce type I collagen mRNA and protein was verified by RT-PCR and immunocytochemistry. These observations suggest that differentiated fibrocytes may play the same role as fibroblasts in collagen production after migration into the extracellular matrix. Although previous studies have shown that fibrocytes have fibroblast-like features, there is no information on their size. Our results showed that fibrocytes are slightly larger than fibroblasts; however, the size distributions overlap. The fact that the fibrocytes have a low proliferation rate suggests that these cells may be terminally differentiated cells in our cell culture system; but this may not be the case in vivo. Identification of a specific marker for fibrocytes would permit labeling of these cells in wound tissue and is currently being investigated in our laboratory.

We found in this study that the percentage of collagen-producing fibrocytes was significantly increased, and differentiated fibrocytes persisted longer in cultures of PBMC from burn patients compared with controls. This is reminiscent of the report by Labat et al (1994) who found that the persistence of fibroblastlike cells was abnormally long in cultures of PBMC from a patient who had developed pulmonary fibrosis after cardiac transplantation and cyclosporine therapy. The alteration of fibrocyte morphology and the increase in fibrocyte number in patients with large burn injuries could be pathologic consequences of the dysregulation of immune function or of changes in circulating cytokines after injury. The smaller burn 

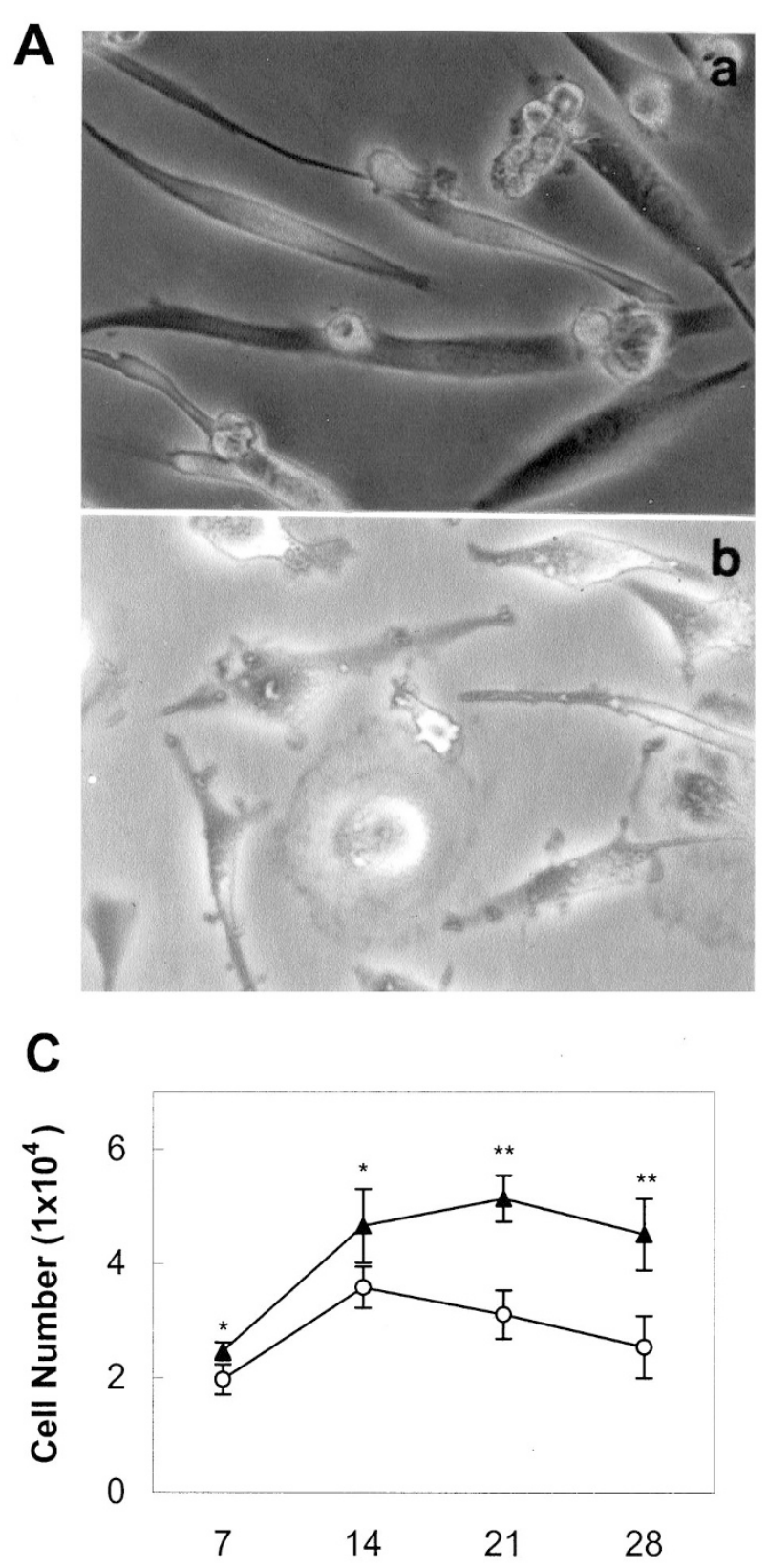

\section{Days of Culture}

B
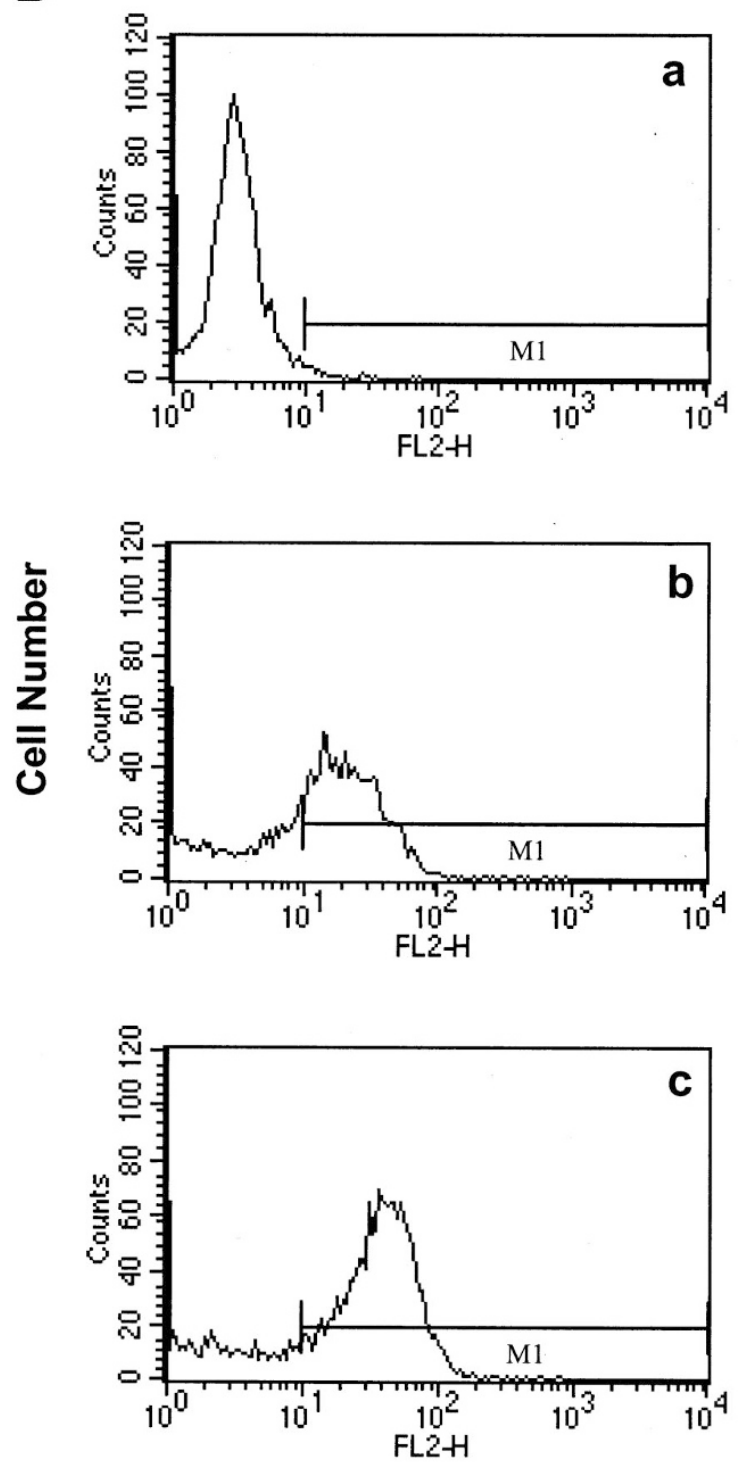

Fluorescence Intensity

\section{Figure 7.}

The effects of TGF- $\beta 1$ on fibrocyte growth and function. Total PBMC isolated from the blood of normal individuals were cultured in duplicate on 6 -well plates at 5 $\times 10^{6} /$ well. After 4 days, cells were treated with or without recombinant human TGF- $\beta 1(2.5 \mathrm{ng} / \mathrm{ml})$. After 28 days the cells were photographed (A). TGF- $\beta$-treated cells display a more fibroblast-like morphology (a), whereas untreated cells become large and swollen (b). B, Flow cytometric analysis showed that the percentage of collagen type I-positive cells was increased by TGF- $\beta 1$ (c) compared with untreated cultures (b). An IgG control is shown in panel a. C, The effect of TGF- $\beta 1$ on fibrocyte proliferation was assessed by cell counting. Addition of TGF- $\beta 1$ to the cell cultures $(\mathbf{\Delta})$ significantly increased the number of fibrocytes compared with controls $(0)$ at all time points tested. The data represent mean values \pm SD of three separate experiments, each examined in duplicate with significant differences at ${ }^{\star} p<0.05$ or ${ }^{* *} p<0.01$ ( $t$ test).

injury might not trigger the significant adaptive immune response required to have this effect.

Investigation of the cellular origin of fibrocytes, and the requirements for their development, could provide the basis for understanding the mechanisms underlying the changes in fibrocytes after burn injury. Therefore we separated CD14 ${ }^{+}$and CD14 ${ }^{-}$cells and demonstrated that fibrocytes developed in culture only from the former. However, the number of fibrocytes that differentiated from a population of highly purified

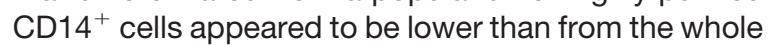
PBMC. Similarly, we found that removal of nonadherent PBMC from adherent cells after overnight culture reduced the total number of adherent cells and the percentage of collagen $\mathrm{I}^{+}$cells obtained after 14 days of culture. These observations are consistent with a 
recent report indicating that fibrocyte differentiation requires interaction between an adherent population of CD14 ${ }^{+}$-enriched peripheral blood cells and T cells (Abe et al, 2001). It suggests that CD14- lymphocytes or cytokines produced by these cells play some role in fibrocyte development. To address this issue, we tested the effects of conditioned medium from $\mathrm{CD} 14^{-}$ lymphocytes on $\mathrm{CD}_{14}{ }^{+}$cells and found, in contrast to the report by Abe and colleagues, that this medium enhanced fibrocyte differentiation, whereas direct contact with $\mathrm{CD} 14^{-}$cells was unnecessary. Based on the observations reported here that TGF- $\beta 1$ can mimic the effects of $\mathrm{CD}_{14}{ }^{-}$cell-conditioned medium on fibrocyte development, and that inclusion of antiTGF- $\beta 1$ antiserum blocks it, we suggest that this stimulator for fibrocytes in the conditioned medium is in fact TGF- $\beta 1$.

In view of these in vitro findings, we measured the levels of TGF- $\beta$ in serum of the burn patients from whom the PBMC were obtained. Consistent with our previous studies (Tredget et al, 1998), we observed increased serum TGF- $\beta 1$ in patients with large burn injuries. Moreover, the levels of serum TGF- $\beta 1$ in the individual patients seemed to be positively correlated with the percentages of fibrocytes found in PBMC cultures. In the absence of a physical model and to apply some preliminary statistical analysis, we evaluated this correlation by linear regression. The true relationship is probably more complex and nonlinear. TGF- $\beta 1$ is stored at high concentrations in platelets and is released into the wounds by degranulation (Assoian and Sporn, 1986; Massagué, 1990). It can stimulate the production of new TGF- $\beta 1$ by several cell types involved in wound healing including macrophages (Assoian et al, 1987; Rappolee et al, 1998), fibroblasts (Messadi et al, 1994), keratinocytes (Kato et al, 1995), and endothelial cells (Roberts and Sporn, 1996). Increased expression and activation of TGF- $\beta$ in cutaneous wound tissue have been demonstrated in the rodent wound healing models (Yang et al, 1999, 2001). Increased local levels of TGF- $\beta 1$ play an important role in regulating wound inflammatory and immune response (Cerwenka and Swain, 1999; Letterio and Roberts, 1998). Circulating monocytes and activated lymphocytes also produce TGF- $\beta$ (Grotendorst et al, 1989; Kehrl et al, 1986). Enhanced activity of the immune cells after extensive burn injury could possibly cause an increase in serum TGF- $\beta 1$.

A highly potent effect of TGF- $\beta 1$ in wound repair is the stimulation of fibroblasts to produce extracellular matrix proteins such as type I collagen (Ignotz and Massagué, 1986; Varga and Jimenez, 1986). Our in vitro data showed that TGF- $\beta 1$ strongly enhanced fibrocyte proliferation and differentiation and collagen production. Abe et al (2001) similarly reported that TGF- $\beta$ caused a dose-dependent increase in the number of fibrocytes. Overexpression of TGF- $\beta 1$ has been implicated in various forms of fibrosis such as glomerulonephritis (Border et al, 1990), liver cirrhosis (Castilla et al, 1991), and pulmonary fibrosis (Broekelmann et al, 1991) as well as hypertrophic scar (Ghahary et al, 1993). Although increased fibrocytes and collagen production after burn injury could accelerate wound repair, an interaction between elevated serum TGF- $\beta 1$ and fibrocyte differentiation may contribute to hypertrophic scar formation in healing burn wounds.

\section{Materials and Methods}

\section{Patients and Clinical Samples}

Eighteen burn patients ( 13 men and 5 women) who were treated at the Firefighters' Burn Treatment Unit and Outpatient Burn Clinic at the University of Alberta Hospital were entered into the study after providing informed consent. The median age was $32.8 \pm 13.6$ (range, 13-59) years. The clinical characteristics of the patients are presented in Table 1. The control population consisted of 12 healthy age- and sex-matched volunteers with ages ranging from 19 to 43 years. This protocol was approved by the Health Research Ethics Board of the University of Alberta Hospital.

\section{Preparation of Fibrocytes}

Human blood-borne fibrocytes were isolated from peripheral blood and cultured as previously described (Bucala et al, 1994; Chesney et al, 1997) with some modifications. Briefly, samples of 25 to $30 \mathrm{ml}$ of blood were drawn into heparinized tubes from burn patients at various times after injury and from normal individuals. Total PBMC were isolated by density gradient sedimentation on HistoPaque 1077 (Sigma Chemical Co., St. Louis, Missouri) following the manufacturer's protocol. The cells were stored frozen in liquid nitrogen until use. Frozen PBMC were thawed and cultured on 6 -well plates at $5 \times 10^{6}$ cells per well, in DMEM supplemented with $10 \%$ heat-inactivated fetal bovine serum, L-glutamine (2 mm), penicillin (100 U/ml), streptomycin $(100 \mu \mathrm{g} / \mathrm{ml})$, and amphotericin B $(0.25 \mu \mathrm{g} / \mathrm{ml})$ (Life Technologies, Grand Island, New York). After 3 days, nonadherent cells were removed by a single aspiration, and the medium was changed. After 10 days of culture, the adherent cells were harvested by incubation with cold $0.05 \%$ EDTA in PBS and gentle scraping with a rubber policeman. Cells were counted using a hemocytometer.

\section{Immunomagnetic Selection of $\mathrm{CD} 14^{+}$and $\mathrm{CD}^{-} 4^{-}$Cells}

To study the origin of fibrocytes, CD14 ${ }^{+}$cells were purified by MACS according to the manufacturer's protocol (Miltenyi Biotec, Auburn, California). Briefly, $10^{7}$ PBMC were resuspended in $60 \mu \mathrm{l}$ of cold PBS containing $0.5 \%$ BSA and 2 mM EDTA (MACS buffer). Forty microliters of MicroBeads conjugated with a mouse anti-human CD14 IgG2a (Miltenyi Biotec) were added to the cells and incubated for 15 minutes at $4^{\circ} \mathrm{C}$. Cells were washed and resuspended in $1 \mathrm{ml}$ of MACS buffer and then applied to a pre-equilibrated sterile LS separation column (Miltenyi Biotec) placed in a MidiMACS magnet. The column was washed three times with MACS buffer, and the total flowthrough, including washes, was collected as the $\mathrm{CD}_{14}{ }^{-}$fraction. The $\mathrm{CD} 14^{+}$cells were eluted after 
Table 1. Clinical Characteristics of Burn Patients

\begin{tabular}{|c|c|c|c|c|}
\hline Patient no. & Age (years) & Sex & TBSA (\%) & $\begin{array}{l}\text { Time of sample collection } \\
\text { (days postburn) }\end{array}$ \\
\hline 1 & 47 & Man & 40 & 19 \\
\hline 2 & 48 & Woman & 40 & $48,300,397$ \\
\hline 3 & 23 & Woman & 85 & $28,79,160$ \\
\hline 4 & 29 & Man & 50 & $9,18,34,89,260$ \\
\hline 5 & 37 & Man & 50 & $38,54,170$ \\
\hline 6 & 19 & Man & 75 & 42 \\
\hline 7 & 37 & Man & 75 & 15,120 \\
\hline 8 & 26 & Man & 35 & $18,29,104,169$ \\
\hline 9 & 19 & Woman & 50 & $12,32,52$ \\
\hline 10 & 20 & Man & 45 & 61 \\
\hline 11 & 56 & Man & 45 & 113 \\
\hline 12 & 25 & Man & 40 & 36 \\
\hline 13 & 13 & Man & 35 & 12 \\
\hline 14 & 35 & Woman & 35 & 142 \\
\hline 15 & 47 & Man & 10 & $34,69,90,167$ \\
\hline 16 & 27 & Man & 25 & 100 \\
\hline 17 & 24 & Man & 18 & 18 \\
\hline 18 & 59 & Woman & 15 & 9 \\
\hline Mean $\pm S D$ & $32.8 \pm 13.6$ & $\begin{array}{c}5 \text { women } \\
13 \text { men }\end{array}$ & $\begin{array}{l}4:<30 \% \\
14: \geq 30 \%\end{array}$ & \\
\hline
\end{tabular}

removal of the column from the magnet with $5 \mathrm{ml}$ of MACS buffer. The purity of the cell populations was assessed by fluorescence staining for CD14 with FITC-conjugated mouse anti-human CD14 antibody (BD PharMingen, San Diego, California) and flow cytometric analysis, as described later. CD14 ${ }^{+}$and CD14 ${ }^{-}$cells were cultured separately in 6-well plates to determine the cellular source of fibrocytes.

\section{Measurement of the Size of Fibrocytes}

The size of fibrocytes in suspension was measured using a Coulter Counter (model ZM; Buffalo, New York). Briefly, after 14 days of culture, adherent cells were harvested by incubation with trypsin/EDTA and resuspended in cell culture medium. Standard polystyrene beads, $22.0 \mu \mathrm{m}$ in diameter (Polysciences Inc., Warrington, Pennsylvania), were used to calibrate the counter. Samples were counted with a window of $1 \mu \mathrm{m}$ diameter between 11 and $26 \mu \mathrm{m}$. The size of normal human fibroblasts cultured from punch biopsy specimens of uninjured skin was also measured.

\section{RT-PCR for Type I Collagen mRNA}

RT-PCR was performed to detect mRNA for the pro $\alpha 1$ (I) chain of type I collagen in fibrocytes after 14 days of culture. Total RNA was extracted from cultured fibrocytes using the guanidinium isothiocyanate/phenol technique as previously described (Ghahary et al, 1994). Subsequently, RNA was reverse transcribed at $42^{\circ} \mathrm{C}$ for 1 hour in reactions consisting of $2 \mu \mathrm{g}$ of total RNA, $1 \mu$ l of random oligonucleotide primers, $1 \mu \mathrm{l}$ of $20 \mathrm{~mm}$ dithiothreitol, $1 \mu \mathrm{l}$ of $10 \mathrm{~mm}$ dNTP mix, $200 \mathrm{U}$ of Maloney murine leukemia virus reverse transcriptase
(Life Technologies) and $2 \mu$ of cDNA synthesis buffer made up to $10 \mu \mathrm{l}$ with diethylpyrocarbonate-treated double-distilled water (Hopkinson et al, 1995).

The cDNA products were amplified by PCR using primers specific for human pro $\alpha 1$ (I) of type I collagen with sequences of sense primer 5'-CGA TGG ATT CCA GTI CGA GTA-3' and antisense primer 5'-GTT TAC AGG AAG CAG ACA GG- 3', yielding a 405-bp product. PCR reactions consisted of $1 \mu \mathrm{l}$ of CDNA, $1 \mu \mathrm{l}$ of $50 \mathrm{pmol}$ of each primer, $1 \mu \mathrm{l}$ of $10 \mathrm{~mm}$ dNTP mix, 2.5 $\mathrm{U}$ of Taq polymerase (Sigma), and $5 \mu \mathrm{l}$ of $10 \times$ PCR buffer provided with the enzyme made up to $50 \mu \mathrm{l}$ with sterile HPLC water. PCR amplification was performed in a RoboCycle Gradient 40 (Stratagene Cloning Systems, La Jolla, California) using 35 cycles of denaturation at $95^{\circ} \mathrm{C}$ for 75 seconds, annealing at $55^{\circ} \mathrm{C}$ for 75 seconds, and extension at $72^{\circ} \mathrm{C}$ for 75 seconds, with an initial denaturation at $95^{\circ} \mathrm{C}$ for 60 seconds and a final extension at $72^{\circ} \mathrm{C}$ for 10 minutes. Amplification of $\beta$-actin cDNA in these samples served as an internal control using sense primer 5 '-CCC CCA TGC CAT CCT GCG TCT G-3' and antisense primer 5'-CAT GAT GGA GTT GAA GGT AGT TT-3', yielding a 337-bp product. The PCR products $(20 \mu \mathrm{l})$ were separated by electrophoresis on a $1.2 \%$ agarose gel stained with ethidium bromide. The bands were visualized and photographed over an ultraviolet light.

\section{Immunocytochemistry of Cultured Fibrocytes}

Adherent cells were subcultured on sterile coverslips for 3 days. Immunostaining for type I collagen was performed using the avidin-biotin immunoperoxidase staining technique. Cells cultured on coverslips were washed in PBS and fixed in acetone for 5 minutes at 
room temperature. The primary antibody, a mouse anti-human type I collagen IgG (Chemicon, Temecula, California), was applied to cells at a concentration of $10 \mu \mathrm{g} / \mathrm{ml}$ in PBS and incubated for 1 hour at room temperature. Cells were washed in PBS and then incubated with a biotinylated goat anti-mouse secondary antibody (1:200 dilution; Vector Laboratories, Burlingame, California) for 30 minutes at room temperature. After washing in PBS, cells were incubated with the avidin-biotin complex (ABC kit; DAKO Diagnostics Canada Inc., Mississauga, Ontario, Canada) for 40 minutes at room temperature. Cells were washed and then incubated for 3 minutes with the peroxidase substrate, 3-amino-9-ethylcarbazole (DAKO). Finally, cells were counterstained with hematoxylin and mounted in AquaPerm mounting medium (Shandon, Pittsburgh, Pennsylvania). The stained cells were visualized using a Nikon microscope and photographed using Kodak Ektachrome 200 ASA color film (Eastman-Kodak, Rochester, New York).

\section{Flow Cytometry of Cultured Fibrocytes}

The adherent cells cultured from PBMC were harvested by incubation with cold $0.05 \%$ EDTA in PBS. After centrifugation, cells were aliquoted to $10^{5}$ cells per FACS tube. Cells were fixed in cold $70 \%$ ethanol for 30 minutes at $4^{\circ} \mathrm{C}$ and washed in cold PBS containing $3 \%$ BSA and $0.1 \%$ sodium azide (FACS buffer). Cell pellets were resuspended in $100 \mu \mathrm{l}$ of FACS buffer and incubated with a mouse anti-human type I collagen antibody (Chemicon) at a concentration of $10 \mu \mathrm{g} / \mathrm{ml}$ for 30 minutes at $4^{\circ} \mathrm{C}$. Isotype-matched mouse IgG was used as a control. Cells were washed and then resuspended in $100 \mu \mathrm{I}$ of FACS buffer. Two microliters of phycoerythrin-conjugated goat antimouse secondary antibody (Sigma) were added to cells, which were then incubated in the dark for 30 minutes at $4^{\circ} \mathrm{C}$. After washing, cells were resuspended in FACS buffer. Fluorescently labeled fibrocytes were analyzed in a FACScan flow cytometer (Becton-Dickinson, Mississauga, Ontario) using the CellQuest software. At least 5000 events were acquired for each sample.

\section{ELISA for Serum TGF- $\beta 1$}

The levels of serum TGF- $\beta 1$ were measured using ELISA as previously described (Tredget et al, 1998; Yang et al, 2000). Briefly, 96-well ELISA plates were coated with the capture antibody (mouse anti-human TGF- $\beta 1$; Genzyme, Cambridge, Massachusetts) at $100 \mu \mathrm{l}$ per well and incubated overnight at $4^{\circ} \mathrm{C}$. The plates were washed in PBS-Tween 20 (PBS-T) and blocked with $1 \%$ BSA. Diluted and acidified samples or serial dilutions of recombinant human TGF- $\beta 1$ (R\&D Systems) were added in triplicate to the plates, which were then incubated for 60 minutes at $37^{\circ} \mathrm{C}$, followed by washing with PBS-T. One hundred microliters of the secondary antibody (chicken anti-human TGF- $\beta 1$; $R \& D$ Systems) were added to the plates at a concentration of $2.5 \mu \mathrm{g} / \mathrm{ml}$ and incubated for 60 minutes at $37^{\circ} \mathrm{C}$, followed by washing with PBS-T. The third antibody, alkaline phosphate-conjugated rabbit antichicken IgG (Sigma), was added and incubated for 60 minutes at $37^{\circ} \mathrm{C}$. After washing, o-nitrophenylphosphate (Sigma) was added to the plates, which were incubated for 40 minutes at room temperature. The optical density was measured using a THERMOmax microplate reader (Molecular Devices, Menlo Park, California) at a wavelength of $405 \mathrm{~nm}$.

\section{Statistical Analysis}

The percentage of fibrocytes and the levels of serum TGF- $\beta 1$ were compared using one-way analysis of variance. The numbers of fibrocytes obtained in cultures with or without TGF- $\beta 1$ were compared using the Student's $t$ test. Correlations between the serum TGF- $\beta$ levels and the percentage of fibrocytes were assessed by linear regression using GraphPad Prism software. For all comparisons a value of $p<0.05$ was considered to be significant. All data are expressed as mean values \pm SD.

\section{Acknowledgements}

We thank Ms. Carole Dodd for her assistance of measuring the size of cells and Mr. Naaman Shaikh of Miltenyi Biotec Inc. for technical help.

\section{References}

Abe R, Donnelly SC, Peng T, Bucala R, and Metz CN (2001). Peripheral blood fibrocytes: Differentiation pathway and migration to wound sites. J Immunol 166:7556-7562.

Assoian RK, Fleurdelys BE, Stevenson HC, Miller PJ, Madtes DK, Raines EW, Rose R, and Sporn MB (1987). Expression and secretion of type beta transforming growth factor by activated human macrophages. Proc Natl Acad Sci USA 84:6020-6024.

Assoian RK and Sporn MB (1986). Type $\beta$ transforming growth factor in human platelets: Release during platelet degranulation and action on vascular smooth muscle cells. J Cell Biol 102:1217-1223.

Border WA, Okuda S, Languino LR, Sporn MB, and Ruoslahti E (1990). Suppression of experimental glomerulonephritis by antiserum against transforming growth factor $\beta 1$. Nature 346:371-374.

Broekelmann TJ, Limper AH, Colby TV, and McDonald JA (1991). Transforming growth factor $\beta 1$ is present at sites of extracellular matrix gene expression in human pulmonary fibrosis. Proc Natl Acad Sci USA 88:6642-6646.

Bucala R, Spiegel LA, Chesney J, Hogan M, and Cerami A (1994). Circulating fibrocytes define a new leukocyte subpopulation that mediates tissue repair. Mol Med 1:71-81.

Castilla A, Prieto J, and Fausto N (1991). Transforming growth factor $\beta$ and $\alpha$ in chronic liver disease. $\mathrm{N}$ Engl $\mathrm{J}$ Med 324:933-940.

Cerwenka A and Swain SL (1999). TGF- $\beta 1$ : Immunosuppressant and viability factor for $\mathrm{T}$ lymphocytes. Microbes Infect 1291-1296.

Chesney J, Bacher M, Bender A, and Bucala R (1997). The peripheral blood fibrocyte is a potent antigen-presenting cell 
capable of priming naïve T cells in situ. Proc Natl Acad Sci USA 94:6307-6312.

Chesney J, Metz C, Stavitsky AB, Bacher M, and Bucala R (1998). Regulated production of type I collagen and inflammatory cytokines by peripheral blood fibrocytes. J Immunol 160:419-425.

Ghahary A, Shen YJ, Scott PG, Gong Y, and Tredget EE (1993). Enhanced expression of mRNA for transforming growth factor- $\beta$, type I and III procollagen in human postburn hypertrophic scar tissues. J Lab Clin Med 122:465-473.

Ghahary A, Shen YJ, Scott PG, and Tredget EE (1994). Expression of mRNA for transforming growth factor- $\beta 1$ is reduced in hypertrophic scar and normal dermal fibroblasts following serial passage in vitro. J Invest Dermatol 103:684686.

Grab DJ, Lanners H-N, Martin LN, Chesney J, Cai C, Adkisson HD, and Bucala R (1999). Interaction of Borrelia burgdorferi with peripheral blood fibrocytes, antigen-presenting cells with the potential for connective tissue targeting. Mol Med 5:46-54.

Grotendorst GR, Smale G, and Pencev D (1989). Production of transforming growth beta by human peripheral blood monocytes and neutrophils. J Cell Physiol 140:396-402.

Hartlapp I, Abe R, Saeed RW, Peng T, Voelter W, Bucala R, and Metz CN (2001). Fibrocytes induce an angiogenic phenotype in cultured endothelial cells and promote angiogenesis in vivo. FASEB J 15:2215-2224.

Hopkinson I, Evans W, Chant D, Hiscox S, Berry D, and Harding K (1995). Reverse transcription-polymerase chain reaction detection of collagen transcripts in healing human wounds. Eur J Clin Invest 25:539-542.

Ignotz RA and Massagué J (1986). Transforming growth factor- $\beta$ stimulates the expression of fibronectin and collagen and their incorporation into extracellular matrix. J Biol Chem 261:4337-4345.

Kato M, Ishizaki A, Hellman U, Wernstedt C, Kyogoku M, Miyazono K, Heldin C-H, and Funa K (1995). A human keratinocyte cell line produces two autocrine growth inhibitors, transforming growth factor- $\beta$ and insulin-like growth factor binding protein-6, in a calcium- and cell densitydependent manner. J Biol Chem 270:12373-12379.

Kehrl JH, Wakefield LM, Roberts AB, Jakowlew S, AlvarezMon M, Derynck B, Sporn MB, and Fauci AS (1986). Production of transforming growth factor $\beta$ by human T lymphocytes and its potential role in the regulation of $T$ cell growth. J Exp Med 163:1037-1050.

Labat ML, Bringuier AF, Arys-Philippart C, Arys A, and Wellens $F$ (1994). Monocytic origin of fibrosis. In vitro transformation of HLA-DR monocytes into neo-fibroblasts: Inhibitory effect of all-trans retinoic acid on this process. Biomed Pharmacother 48:103-111.
Letterio JJ and Roberts $A B$ (1998). Regulation of immune responses by TGF- $\beta$. Annu Rev Immunol 16:137-161.

Massagué J (1990) The transforming growth factor- $\beta$ family. Annu Rev Cell Biol 6:597-641.

Messadi DV, Berg S, Shung-Cho K, Lesavoy M, and Bertolami CN (1994). Autocrine TGF- $\beta 1$ activity and glycosaminoglycan synthesis by human cutaneous scar fibroblasts. Wound Rep Reg 2:284-291.

O'Kane S and Ferguson MWJ (1997). Transforming growth factor $\beta$ s and wound healing. Int J Biochem Cell Biol 29:6378.

Rappolee DA, Mark D, Banda MJ, and Werb Z (1998). Wound macrophages express TGF- $\alpha$ and other growth factors in vivo: Analysis by mRNA phenotyping. Science 241:708-712.

Roberts $A B$ and Sporn MB (1996). Transforming growth factor- $\beta$. In: Clark RAF, editor. The molecular and cellular biology of wound repair. New York: Plenum Press, 275-308.

Scott PG, Ghahary A, and Tredget EE (2000). Molecular and cellular aspects of fibrosis following thermal injury. Hand Clin 16:271-287.

Singer AJ and Clark RAF (1999). Cutaneous wound healing. N Engl J Med 341:738-746.

Tredget EE, Nedelec B, Scott PG, and Ghahary A (1997). Hypertrophic scars, keloid, and contractures: The cellular and molecular basis for therapy. Surg Clin North Am 77:701730.

Tredget EE, Shankowsky HA, Pannu R, Nedelec B, Iwashina T, Ghahary A, Taerum TV, and Scott PG (1998). Transforming growth factor- $\beta$ in thermally injured patients with hypertrophic scars: Effects of interferon $\alpha-2 b$. Plast Reconstr Surg 102:1317-1328.

Varga J and Jimenez SA (1986). Stimulation of normal human fibroblast collagen production and processing by transforming growth factor- $\beta$. Biochem Biophys Res Commun 138: 974-980.

Yang L, Chan T, Demare J, Iwashina T, Ghahary A, Scott PG, and Tredget EE (2001). Healing of burn wounds in transgenic mice overexpressing transforming growth factor- $\beta 1$ in the epidermis. Am J Pathol 159:2147-2157.

Yang L, Qiu CX, Ludlow A, Ferguson MWJ, and Brunner G (1999). Active TGF- $\beta$ in wound repair: Determination using a new assay. Am J Pathol 154:105-111.

Yang L, Tredget EE, and Ghahary A (2000). Activation of latent transforming growth factor- $\beta 1$ is induced by mannose 6 -phosphate/insulin-like growth factor-II receptor. Wound Rep Reg 8:538-546. 